Estudios Románicos, Volumen 28, 2019, pp. 139-149

ISSN: 0210-491

eISSN: 1989-614X

DOI: https://doi.org/10.6018/ER/377761

\title{
LA ESCRITURA EPISTOLAR ENTRE PASADO Y PRESENTE: HABITACIONES CERRADAS DE CARE SANTOS
}

(Epistolary writing between past and present: Habitaciones Cerradas by Care Santos)

\author{
Giulia Tosolini* \\ Università degli Studi di Udine (Italia)
}

\begin{abstract}
The article focuses on how letters, mails and self-writing are used in the fragmented narrative scheme of Habitaciones cerradas (2011) by Care Santos. The novel is a family saga developing two parallel plots, jumping around space and time in order to keep the reader attentive and to return the structure of memories, while offering useful details to solve the mystery that narration develops.
\end{abstract}

Keywords: Epistolary Literature; Contemporary Spanish Literature; Female Literature.

Resumen: El artículo se propone analizar la fragmentación narrativa creada por el uso de cartas, correos electrónicos y "escrituras del yo" en el esquema narrativo de $\mathrm{Ha}$ bitaciones cerradas (2011) de Care Santos, muestra de la literatura femenina española contemporánea. En la novela, una saga familiar con dos tramas paralelas, los saltos temporales y espaciales que mantienen viva la atención del lector, y a la vez, recrean el flujo de los recuerdos, se crean también gracias a las cartas colocadas a lo largo de la novela, que, simultáneamente, ofrecen detalles para la solución del misterio que encierra la narración.

Palabras clave: Literatura epistolar; Literatura española contemporánea; Literatura femenina.

* Dirección para correspondencia: Giulia Tosolini. Dipartimento di Lingue e Letterature Straniere, Formazione, Comunicazione e Società (DILL). Università degli Studi di Udine. Via Petracco, 8, 33100, Udine, Italia (giulia. tosolini@uniud.it). 
Para Care Santos, exitosa autora catalana del panorama contemporáneo, su séptima novela ${ }^{1}$, Habitaciones cerradas ${ }^{2}$, ha representado un punto de inflexión en su trayectoria literaria, un importante gasto de energías, pero, en fin, el que ella considera su mejor libro3.

La familia Lax y sus secretos son los protagonistas de esta saga folletinesca barcelonesa, de palpables ejes rodoredianos ${ }^{4}$, que sorprende al lector no solo por una doble trama sino por su estructura narrativa ${ }^{5}$, en la realización de un ejercicio de la memoria ligado al quehacer literario. La fragmentación del texto, la hibridación y la pluralidad de fuentes, en una "ficción [que] se hace con la historia o con la imaginación" (Gracia; Ródenas 2011: 974) en un mutuo y equilibrado intercambio, responden a la tendencia literaria femenina de las últimas décadas ${ }^{6}$ y posiblemente a una exigencia explícita ${ }^{7}$ de la autora, que, mezclando personajes, acontecimientos y fechas reales con la ficción, procura brindar verosimilitud a hechos que no la tendrían y, a la vez, exaltar el valor de los recuerdos, con el desorden paradójicamente lógico de cuando se vienen a la mente, en una mímesis de la realidad.

Desde esta óptica hay que considerar la presencia de algunas manifestaciones textuales ficticias de intercomunicación entre los distintos personajes, separadas gráficamente de las secuencias narrativas, descriptivas, reflexivas o dialógicas de los veintiséis capítulos de la novela. De hecho, contamos con ocho écfrasis de cuadros procedentes de ficticios catálogos museales o publicaciones artísticas, tres cartas, cuatro artículos de periódicos, dos páginas de un diario Moleskine, veintidós correos electrónicos, un verbal de los Mossos d'Esquadra, un extracto de blog, un inventario de obras de arte, un acta de la asamblea del patronato del Museu Nacional d'Art de Catalunya, un informe y un artículo de revista. A lo largo de la novela a esto se añaden citas parciales o completas de cartas, telegramas y tarjetas.

1 Considerando las novelas para adultos que Santos empieza a escribir a partir de 1997. De hecho, no se cuentan las veintisiete novelas para jóvenes y las diecisiete para niños.

2 La novela fue publicada en español y en catalán (Habitacions Tancades) en 2011 por Planeta, vendiendo respectivamente 25.000 y 20.000 copias. Además, se tradujo a doce lenguas, publicándose en Portugal (Planeta Manuscrito), Italia (Salani), Rumania (Humanitas), Países Bajos (Wereldbibliotheek), Suecia (Albert Bonniers Förlag), Noruega (Cappelen Damm), Alemania (Fischer), Francia (Grasset), Polonia (Sonia Draga), Grecia (Psichogios), Lituania (Alma Littera) y Brasil (Record). En 2014 el director Lluis Maria Güell empezó el rodaje de la serie televisiva homónima, transmitida en dos episodios en noviembre de 2015 en La1 de TVE.

3 Las declaraciones de la autora, además de la prensa nacional e internacional, están sacadas de su página web http://www.caresantos.com/.

4 Santos reconoce a Mercé Rodoreda como uno de los "autores que me habían de marcar y acompañar para siempre" (Santos; García Ríos 2016: 113) en más de una ocasión. De todas las obras rodoredianas Habitaciones cerradas evoca una importante intertextualidad con Mirall trencat (Espejo roto): aparte de la fragmentación narrativa, de la ambientación en una Barcelona modernista, del punto de vista femenino y de la homonimia entre las protagonistas, las dos sagas familiares comparten tópicos temáticos (la memoria, el tiempo, la muerte, la importancia del arte), la superposición del plan histórico con el ficcional, y la eficacia de las descripciones.

$5 \quad$ Referencias narratológicas: Vallés Calatrava (2008); Cuvardic García (2014).

$6 \quad$ Cf. Gracia y Ródenas (2011); Hermosilla Álvarez y Cepedello Moreno (2013).

$7 \quad$ Al final de la novela aparecen un árbol genealógico de la familia Lax, el Dramatis personae con la lista de personajes reales y ficticios y una nota de la autora donde se especifica que "Habitaciones cerradas es, a pesar de su documentada ambientación histórica, una obra de ficción” (Santos 2011: 489). 
Muy típica de la narración femenina, esta "perspectiva múltiple"8:

esta multiplicación del aspecto en el sentido narratológico del término [...] requiere el despliegue de distintas técnicas narrativas de las que se valen las autoras para dar cabida en el discurso a otros puntos de vista, otras maneras de analizar la realidad que rodea a los protagonistas y que da como resultado un relato caleidoscópico donde las partes se han convertido en piezas de un puzle que el lector tiene que encajar. (Hermosilla Álvarez; Cepedello Moreno 2013: 266)

Las dos tramas, que responden a la necesidad de alejarse de una narración estática y monorreferencial, corresponden a dos directrices temporales distintas. Una se desarrolla en el presente, con Violeta Lax, experta de arte, que de Chicago se mueve a Barcelona en principio para resolver unas cuestiones hereditarias (la abertura de un museo dedicado a su abuelo, el pintor Amadeo Lax, en la que fue la casa de su familia ahora gestionada por la Generalitat), sin saber que su estancia se prolongará al descubrirse, en la vivienda, un cadáver momificado. Su viaje la llevará también a Italia, ofreciéndole la posibilidad de encontrarse con unos vínculos familiares inesperados. La otra cuenta los avatares de la familia Lax entre finales del siglo XIX y el estallido de la Guerra Civil. Las dos líneas temáticas comparten, además de los protagonistas, también el espacio: el lector se encuentra en la Barcelona modernista de los grandes almacenes El Siglo, de las reuniones espiritistas de los miércoles en casa de don Rodolfo Lax y María del Roser Golorons, de las huelgas obreras, en el bullicio y el fermento de sus calles, y, de repente, tropieza con la contemporánea y caótica Rambla llena de turistas en primavera.

La acción narrativa y los acontecimientos no siguen un orden causal y cronológico, están hábilmente ofrecidos a través de analepsis y prolepsis, con la contribución de las cartas, los correos electrónicos y los documentos que intercalan los capítulos, relatados por un narrador testigo - los fantasmas" de la casa que hacen el "juego de devolver todo a su lugar" (Santos 2011: 472)- que alterna la primera persona plural con la tercera. Las cartas, los correos electrónicos y las otras ficciones textuales crean el contrapunto, mezclando las perspectivas y los planes espacio-temporales, con una focalización múltiple que enriquece la narración ${ }^{10}$. El narrador y el punto de vista cambian en las cartas

8 Como recuerdan Hermosilla Álvarez y Cepedello Moreno (2013), concepto utilizado en 1989 por Marina Mayoral para referirse, en particular, a su obra.

$9 \quad$ En más de una ocasión el narrador se manifiesta: "siempre que ocurre algo así, las piedras y los fantasmas nos alborotamos" (Santos 2011: 51); "es frágil la memoria de nuestros sucesores, susurramos a coro, dando gracias de que algo, aunque sea una parte ínfima y tramposa como el argumento de una novela, dé cuenta de nuestros pasos por el mundo" (Santos 2011: 472).

10 Entre finales del siglo XX y comienzos del XXI, en la literatura en lengua española, peninsular e hispanoamericana, empiezan a aparecer novelas polifónicas en las que los medios virtuales cobran importancia, como reflejo de la evolución tecnológica del mundo que cuentan. Entre otras, Acoso textual (1999), de Raúl Vallejo, se centra en la comunicación en el ciberespacio; El corazón de Voltaire (2005), del ecuatoriano Luis López Nieves, se considera una de las primeras novelas epistolares construida a través de correos electrónicos; la novela polifónica del mallorquín Fernando Alomar, La montaña caníbal (2007), incluye diálogos, diarios, correos electrónicos y mensajes de texto; más reciente, la novela de 2016 de Andrés Neuman, La vida en las ventanas, gracias al uso de los correos electrónicos reflexiona sobre el mundo virtual y la soledad. 
escritas, en los mensajes y en los otros papeles, auténticos mecanismos de la narración, que pasa directamente a los protagonistas, con un cambio repentino y evidente, gracias al

carácter de inmediatez que adquiere la experiencia vivida y relatada, la naturaleza privada de la exposición, con su indagación psicológica y personal, y la esencia dialógica del discurso, $[\ldots]$ se contribuye a la creación de autenticidad de lo contado y de apariencia de no-ficcionalidad (Morales Ladrón 1996: 286),

permitiendo al lector empírico entrar en la mente de quien escribe y contemporáneamente adquirir información para la solución del misterio.

Nuestro análisis se va a centrar en las tres cartas escritas y en los veintidós correos electrónicos, que, además de ofrecer un punto de vista alternativo, responden a la exigencia de romper la narración cronológica para crear saltos, mover la linealidad de la historia según la poética de la autora -"Pienso que el orden cronológico está sobrevalorado. A mí, me aburre bastante. Por eso en todas mis novelas hay alteraciones cronológicas, analepsis, elipsis, prolepsis..." (Santos y García Ríos 2016: 109)- en el que consideramos un diálogo diferido, una conversación alargada en el tiempo, que, de hecho, se descompone; en ellos "il presente della scrittura tende a scomparire, continuamente negato da un'anticipazione che si realizzerà nel passato, prefigurazione di un futuro che ha già avuto luogo" (Patrizia Violi 1984: 91). En este sentido el vaivén cronológico, típico de los recuerdos y del trabajo de la memoria hace que el receptor viva la lectura como una experiencia verosímil extendiendo esta consideración a toda la obra. Además, la escritura epistolar reenvía a un receptor lejano físicamente, "con una relación muy íntima y exclusiva, en el que un personaje describe desde su mismo presente, una realidad que es exterior e interior al mismo tiempo" (Morales Ladrón 1996: 286), igual que los recuerdos fantasmales que constituyen los capítulos narrados, en un paralelismo estructural y temático llamativo, vinculado a la circularidad de la obra.

El protagonismo del tiempo, en su doble vertiente constructora y destructora -confirmado por la cita de la dramaturga francesa Yasmina Reza al comienzo de la novela ${ }^{11}$ - es sustancial a la hora de considerar las cartas, "pero no en su cronología, [...], sino el tiempo vivido, el pasado, cuya recuperación o rememoración se intenta desde un presente que tiende a hacerse intemporal" (Mora 1988: 137), y se anuda con el tema de la ausencia física y emotiva, que, según muchos críticos, es el Leitmotiv que guía la escritura epistolar.

La crítica ha clasificado las cartas y los diarios como "subgéneros femeninos de transición" (Rivas Carmona 1997: 120), reconociendo su tendencia ficcional, junto con el poder y la influencia literaria de un texto tan íntimo como necesariamente dialógico (Guillén 1991). En esta novela contemporánea, cartas y correos adquieren la misma función de transmisión de informaciones en un momento de aislamiento unido a la

11 "El tiempo: el único tema." (Santos 2011: 7), que aparece junto a una cita de Emily Dickinson, otro de los modelos literarios de Santos [Cf. Santos y García Ríos (2016)]. 
urgencia de comunicación y a la expresión de un pensamiento, con peticiones, ruegos o ejercicios de influencia (Petrucci 2008).

Como veremos, la mayoría de los textos epistolares son correos electrónicos -bastante extensos si se considera la brevedad y rapidez que caracteriza este tipo de comunicación - utilizados para mantener o volver a construir ataduras emotivas, para compartir una impotencia frente a la contemporaneidad, a través de un género, desechable y efímero, "usa e getta" (Petrucci 2008). Con los correos, quid de la comunicación virtual, y aparentemente alejados de lo "clásicamente literario" (Marín Abetuya 2004: 741) Santos hace hincapié en la distancia entre las dos épocas y tramas, definiendo la contemporánea con este género textual: su rapidez, su tono coloquial y la ausencia de preámbulos innecesarios son el símbolo de una sociedad y de una relación comunicativa fugaz y afanosa.

En definitiva, también la contraposición de los dos géneros epistolares, cartas y correos electrónicos, es testimonio del paso del tiempo, de la distancia entre presente y pasado, a la que, quizás, solo las obras de arte sobreviven. Aparte de las pinturas de Amadeo Lax, que encontramos intactas en el presente, en las salas museales, como en el pasado, en la buhardilla de la casa donde se retiraba a pintar, el personaje de Arcadio Pérez, último secretario del difunto artista e intermediario con el que se relaciona Violeta para las cuestiones que atañen la gestión del inmueble, representa un lazo que anuda dos periodos. Un trait d'union como es también el espacio doméstico: en las habitaciones, los salones, los patios y jardines, testigos del día a día de los Lax, ahora mueven sus pasos Violeta, Arcadio, restauradores y policías. Un espacio real, detallado con topónimos y descripciones sinestésicas, para perseguir el elemento de verosimilitud, sin poder escapar a la inflexible ley del tiempo.

A pesar de contar con un protagonista masculino, Amadeo Lax, cuya figura, como veremos, se construye a través de las miradas de las mujeres que lo rodean, la novela alaba a las figuras femeninas, rescatándolas cuando sea necesario, precisamente a través de la memoria. El restablecimiento de la verdad que el lector tiene en sus manos, a diferencia de Violeta, rehabilitará, en el desenlace, la figura de Teresa, acusada de adulterio, cuando en realidad murió asesinada por su marido en una época, la década de los Treinta, en la que todavía la visión patriarcal del mundo dominaba, a pesar de las importantes libertades adquiridas por las mujeres. Teresa muere por querer divorciarse, por afirmar su libertad, como bien le había enseñado su suegra, pionera feminista, "las mujeres somos libres para labrar nuestro futuro y escapar de nuestros explotadores" (Santos 2011: 450).

El primer bloque de escrituras epistolares, puestas antes del primer capítulo, que coloca el lector in medias res, y después de la descripción del fresco Teresa ausente, motor desencadenante de toda la historia, incluye un mensaje electrónico de Silvana Gentile del 8 de febrero de 2010, que anticipa la llegada de la carta escrita en Nesso (Italia) el 10 de febrero por Fiorella Otrante, madre de Silvana, a Violeta Lax. Completan esta sección dos correos electrónicos del 1 de marzo, uno de Violeta a Arcadio Pérez, y otro de su asistenta Drina Walden, con los detalles del viaje de la protagonista a Barcelona. Ya en este último mensaje aparece el tópico del viaje como huida, que se mantendrá 
durante toda la novela: "Ay, Vio, ¿estás segura de que este viaje no es, en realidad una huida? [...] tengo la sospecha de que todo esto tiene más que ver con la crisis de la que me hablaste el otro día" (Santos 2011: 15).

El segundo bloque se encuentra entre los capítulos VII y VIII, cuando el lector ya ha sabido del cadáver momificado escondido detrás del fresco en el patio de la casa que fue de los Lax. Se trata de un correo electrónico del 11 de marzo de Drina a Violeta, donde la asistenta funciona como intermediario, relatando un diálogo mantenido con la madre de su jefa y que el lector desconoce, y de dos correos de la protagonista, ambos enviados el 13 de marzo, a su madre, Valérie Rahal, y a su marido Daniel. En el mensaje a su madre, muy largo, Violeta le pone al día de la aparición del cadáver y de las investigaciones, confesándole sus sospechas sobre la identidad de la muerta, que encontrarán una respuesta en los capítulos siguientes, y pidiéndole averiguar algunas informaciones sobre Francisco Canals Ambrós, cuyo nombre aparecía en la alianza que el cadáver llevaba al cuello. El correo electrónico para su marido desarrolla el mismo tema: "la macabra sorpresa que nos ha deparado la vieja casa de mi familia" (Santos 2011: 115), con un estilo directo y escueto, recapitulando las verificaciones policiales en una lista (esencial para el lector a la hora de reconstruir la identidad de la mujer muerta), citando casi por completo el diálogo que ella tuvo con el sargento.

Sigue, a breve distancia, después del capítulo VIII, un largo mensaje de Violeta a su madre del 15 de marzo: once páginas en las que la narración de los días en Barcelona, del reencuentro con su padre Modesto, hijo de Amadeo y Teresa, se asocia al flujo de la memoria y de los recuerdos; de hecho, el asunto es "Recuperar el tiempo perdido" (Santos 2011: 129). Al admitir que

nunca se me había ocurrido que ésta podía ser una vía de comunicación entre nosotras, pero ahora que la he descubierto, que tengo tiempo y que me encuentro a varios miles de kilómetros de distancia, no pienso desaprovecharla (Santos 2011: 129)

Violeta usa la escritura virtual para anular la distancia y la ausencia que la separa de su madre, pero como en un diario, abre su corazón a sí misma, antes que a su destinataria. La autora empírica, Care Santos, vincula a la elección de este escamoteo narrativo el poder de la palabra que permite construir y revelar los rasgos de quien escribe, caracterizando una de las protagonistas a través de su propia mirada. De hecho, todos los personajes de la novela, los presentes y los pasados, se van dibujando poco a poco, con detalles sobre su físico, su manera de vestir, de hablar y de portarse hábilmente diseminados por toda la novela, con la profundidad emotiva y espontánea típica de la escritura femenina (Ciplijauskaité 1998). Al final de la carta, en un post scriptum, se hace referencia a un correo anterior no reproducido y se anticipa el documento que sigue, el extracto del blog El Santo que nunca lo fue del 31 de octubre de 2007, sobre la figura de Francesc Canals Ambrós, proporcionado a Violeta por su madre.

Después del capítulo IX aparece el siguiente correo de Violeta a Valérie, fechado 20 de marzo de 2010, que confirma la utilidad del medio virtual para el mantenimiento de la relación madre-hija: "Soy mejor hija a distancia. Estos mensajes torrenciales son la 
mayor evidencia" (Santos 2011: 153). Continúa adjuntando informaciones acerca de las pesquisas de Violeta sobre sus antepasados e incluye la descripción de dos fotografías de Amadeo y Teresa, cobrando esta última en la mente de Violeta el valor de abuela, persona, y no solo el de "un motivo artístico, una inspiración afortunada, igualada en rango a las damas de la alta sociedad que gracias al abuelo mantuvieron su encanto y su fama indemnes al paso de las décadas" (Santos 2011: 156).

Para solucionar el misterio de la desaparición de Teresa, que supuestamente abandonó a su marido Amadeo y a su bebé Modesto, huyendo a América con su amante y, en cambio, fue matada y encerrada detrás de un tabique en el patio de su casa, Violeta viaja también a Italia. El correo electrónico del 20 de marzo de 2010 a Arcadio llega "Desde el lago de Como" (Santos 2011: 177) y sirve para aclarar el motivo del primer mensaje y de la primera carta al comienzo de la novela. Maravillada ante el uso de una modalidad comunicativa a la que no está acostumbrada, Violeta se da cuenta de que la escritura funciona como terapia -"Necesito ordenar un poco mis pensamientos. $\mathrm{Si}$ no retengo algo de lo que me está ocurriendo voy a terminar por creer que no es cierto" (Santos 2011: 177)- aprovechando el entorno lacustre, tan inspirador "para enviar cartas largas y decimonónicas" (Santos 2011: 177). La escritura epistolar responde a un "cambio brusco, repentino e imprevisto en el existir del sujeto y es concebida como una mutación importante en el devenir del protagonista" (Caña Jiménez 2012: 35). En el caso del correo electrónico, el contraste entre medio y contenido es otro elemento que resalta la originalidad con la que Santos utiliza la comunicación epistolar en su novela. En Italia Violeta descubre las huellas de su abuelo en treinta y dos lienzos, inventariados en las páginas siguientes por ella misma, junto con el testamento de Eulalia Montull Serrano, cuyos apellidos resultan al lector familiares, que deja las obras que pintó el amor de su vida al Museu Nacional d'Art de Catalunya. El giro inesperado de la historia coge al lector de sorpresa, puesto que al final del correo Silvana explica a Violeta que Amadeo era también su abuelo.

Los siguientes mensajes, colocados entre los capítulos XIV y XX, son envíos y respuestas entre Violeta y su madre. "Circuitos de la memoria" (Santos 2011: 233) es el asunto del correo del 22 de marzo de Valérie a su hija, que intenta retomar el hilo de la historia, proporcionando nuevos detalles cronológicos y, al mismo tiempo, aprovechando la vertiente más íntima de esta tipología textual, intenta aconsejar a su hija sobre cómo gestionar emotivamente el perturbador y sorprendente asunto. En respuesta, el día siguiente, Violeta comparte con su madre el recuerdo del entierro de Teresa y unas teorías sobre los objetos encontrados en la habitación junto con el cadáver. Entre todos es una novela, Espírita -que el lector sabe ser un regalo de María del Roser, mujer moderna y visionaria, que inició a su nuera Teresa en el espiritismo- la que llama la atención de Violeta: el ex libris de Octavio Conde Gómez, íntimo amigo de Lax, encierra un mensaje encriptado, reproducido en el correo, que estimula otras preguntas en la mente ya incitada de quien escribe, Vio. Entre los dos correos el lector se encuentra con la primera de dos páginas del cuaderno Moleskine de Violeta, que apunta una breve reflexión sobre el retrato y su poder engañoso, haciendo aflorar las dudas que la nieta empieza a tener sobre la conducta de su abuelo. A pesar de estas consideraciones, se 
vuelve a afirmar la función del arte como testigo real, que "pronuncia la única verdad que importa" (Santos 2011: 237).

Paralelamente, Violeta aprovecha el canal epistolar con su madre para revelarle un secreto de su adolescencia: su primer amor, un romance barcelonés de 1993, se está muriendo de cáncer y ella quiere despedirse. La revelación íntima hecha por correo en la distancia desvela, quizás, el motivo real de la huida de la crítica de arte de Chicago: volver a Barcelona significa no solo volver a sus raíces, a la historia de su familia, a sus recuerdos, sino volver para cerrar algunas cuentas pendientes con su pasado, que hasta su madre desconoce. El tema del mail "Ya que tanto te interesa..." del 24 de marzo, es precisamente este: la vuelta a España como viaje catártico, en dirección contraria con respecto a la primera huida a Estados Unidos, para "curarme la nostalgia, y [...] olvidar poco a poco mi vida anterior" (Santos 2011: 253).

Retomando el hilo de las investigaciones, el correo de Violeta a su madre del 1 de abril, "Rompecabezas" (Santos 2011: 299), utiliza la comunicación como medio de intercambio de informaciones esenciales o acontecimientos que merecen la pena ser contados: se incluye, de hecho, la crónica de la cena de Violeta y su padre Modesto, en compañía de la asistente Amélie. Valérie, leyendo el correo, se da cuenta de que su hija no ha reconocido que las reacciones de su exmarido esconden el enamoramiento de su joven colaboradora y le pone al tanto de la cosa. Hace referencia también a otros mensajes de Drina, como intermediaria, y no se olvida cerrar el correo con un consejo maternal sobre la cuenta pendiente de Violeta con su amor de juventud. En respuesta, el 3 de abril, con un correo sintético y resolutivo, que respeta la concisión y el éxito comunicativo del género, Violeta confiesa a su madre que su primera relación, por la que se luego se fue a América, fue con una mujer. Una prueba de realismo de Santos, que utiliza esta comunicación virtual y efímera, como hoy en día es costumbre, no solo para conversaciones livianas.

La segunda página del Moleskine de Violeta, de abril de 2010, recoge un inventario de los objetos encontrados en otra habitación cerrada de la casa, el cuarto de Violeta, hermana de Amadeo, que murió a los dieciséis años por leucemia. Aquí se describen con todo detalle también cinco postales del viaje de novios de Amadeo y Teresa en 1928 y un telegrama. La importancia de los objetos, aunque aparentemente triviales y desdeñables, es otro elemento destacable de la poética de Santos: cómo, para la caracterización de los personajes, juntando los pormenores como los hilos de un tapiz, se llega a poder ver el cuadro completo.

Un tercer bloque de correos aparece entre los capítulos XXI y XXII con tres textos: uno de Violeta a Drina, con la respuesta de esta y uno de Daniel a su esposa. La comunicación con Drina es urgente y omite cualquier elemento innecesario, contemplando en la respuesta alterada de la colaboradora americana una expresión jergal ${ }^{12}$. En un juego metaliterario, el correo de Daniel, presencia casi imperceptible, comunica a su mujer la conclusión de la novela en la que estaba trabajando y su consiguiente viaje a Barcelona para celebrar el cuarenta cumpleaños de la madre de sus hijos.

12 "Hace casi dos semanas que tuve que aguantar un chaparrón monumental por dejarles con el culo al aire con el asunto de la entrevista" (Santos 2011: 374). 
Completan el corpus epistolar una carta de Olympia, alias Montserrat Espelleta, a Teresa Brusé, dos correos de Violeta a su madre y las respectivas respuestas, y una carta de Concha a Amadeo Lax, colocados entre el capítulo XXII y el XXVI, el epílogo.

La carta de Olympia (Santos 2011: 389-398) dirigida a la mujer de su amante Amadeo es una emotiva confesión dictada el 12 de febrero de 1930 en el lecho de muerte de la artista. Con todo detalle Montserrat relata las circunstancias que permitieron que su vida de obrera en las fábricas de los Lax se cruzara con la del hijo de su amo, además de ofrecer otro punto de vista sobre los caracteres del jesuita Juan, con el que Amadeo, su hermano, nunca pudo, y del mismo pintor.

En el correo de Violeta a su madre del 11 de abril, “Sigues ahí?”, se mezclan otra vez las noticias sobre las investigaciones, el relato de unos diálogos con su prima recién descubierta, Silvana, y las consideraciones acerca de la propuesta de quedarse en Barcelona para dirigir el futuro museo dedicado a su abuelo Amadeo Lax. Este último asunto, simbólicamente, parece justificar desde otra perspectiva la huida de Chicago, adquiriendo el valor de catarsis, nuevo inicio y absolución para su experiencia, pero, por otro lado, alimenta la inquietud, al saber cómo desapareció su abuela:

Siempre estuve convencida de que el abuelo murió esperándola [...]. De esas ideas románticas ya no queda nada. El abuelo no fue aquel hombre fuerte que yo siempre admiré, [...]. Un homicida, o tal vez un asesino [...]. No sé si quiero dirigir el museo dedicado a un hombre así, mamá. Ni siquiera sé si debe honrar la memoria de ese hombre. (Santos 2011: 421).

La respuesta de su madre, "Estoy aquí", llega al día siguiente, tranquilizándola sobre sus dudas laborales y emotivas, e intentando cerrar el discurso, todavía abierto, de la relación lesbiana adolescente. De nuevo, un abrazo virtual que llega para confortar, una anulación de la distancia, en este caso, también generacional.

Los últimos dos mensajes de Violeta a su madre, respectivamente del 14 y del 16 de abril, están dedicados a los asuntos por resolver de la protagonista: el primero, "El final escatimado" pone un punto a la despedida de su amor, Margot -que nunca la olvidó ${ }^{13}-$, a la que consiguió saludar solo a través de un mensaje dejado a su hija, con la que podemos suponer habrá más charlas. El segundo, "Decisiones", cierra el círculo y pone fin al periplo barcelonés de Violeta, que ha decidido mudarse a España para dirigir el museo. Las dudas pendientes sobre el caso de la muerte de Teresa quedarán sin resolver para ella: el lector empírico sabe por el capítulo XXV cómo y por qué murió la joven madre, y de este modo empatiza con Violeta, que elige su amor por el arte, por sus propios orígenes y familia; al final "el pasado, visto desde el presente, tiene este aspecto: un rompecabezas al que le faltan piezas" (Santos 2011: 212). Sin duda el paréntesis catalán la ha reanimado y fortalecido, en un viaje físico metáfora de la evolución interior, confirmado a su madre con la última despedida virtual "Cojamente tuya, la prolífica, barcelonesa y renovada Violín" (Santos 2011: 463).

13 La canción que aparece citada en el correo, Adiós Vio. Adiós, Violeta, propone el tema de la huida y de la despedida a través de otra manifestación artística y textual, resaltando la heterogeneidad de fuentes y referencias de la novela. 
Antes del epílogo aparece una carta de Concha a su querido Amadeo, que pensaba en Roma, escrita desde Barcelona el 30 de noviembre de 1940. En esta carta la nodriza de la familia Lax relaciona el estado de la casa y de los criados terminada la guerra, con fuerte emotividad y pasión, cerrando la carta con una declaración maternal para el pintor, que pudo criar "como a un hijo" (Santos 2011: 469).

Este análisis nos permite considerar los correos electrónicos como un corpus único que, a pesar de aclarar aspectos importantes de la narración, no podría cumplir su función fuera del contexto ficcional en el que se inserta. Las tres cartas, aún menos. Todos, sin embargo, son imprescindibles para lograr la acertada distorsión cronológica de esta obra, beneficiándose de lo que Bastons i Vivancos (1996) describe como polimorfismo del género. El acceso directo a la subjetividad y a la psicología de los personajes "corrige o complementa la imagen del yo forjada desde fuera" (Rivas Carmona 1997: 24), amplificándola gracias a la relación directa con la oralidad, al gusto por la creación, al carácter intimista y, en cierto sentido, lírico unidos al aspecto autobiográfico de las escrituras epistolares y, por extensión, de una novela escrita por una mujer y que exalta a las mujeres por su fuerza, que sobrevive en los siglos. Sin duda, el estudio permite averiguar que en esta novela los correos electrónicos no solo sirven como medio para crear la polifonía narrativa, hacer más entretenida y apasionante la narración, crear una conexión entre los planos temporales de la obra, sino que se emplean como medio funcional en la descripción, para esbozar la psicología de los emisores, sobre todo de Violeta, y de los receptores, de manera inusual y original.

\section{BIBLIOGRAFÍA}

BASTONS I VIVANCOS, Carles (1996): "Polisemantismo y polimorfismo de la carta en su uso literario". 1616: Anuario de la Sociedad Española de Literatura General y Comparada. X: 233-238. http://www.cervantesvirtual.com/obra/polisemantismoy-polimorfismo-de-la-carta-en-su-uso- literario-0/ [consultado el 08/02/2019]

CAÑA JIMÉNEZ, María del Carmen (2012): "Tiempo/espacio, memoria/narrativa: la novela española finisecular". Letras Hispanas. 8: 33-45. https://www. academia.edu/2194737/ Tiempo espacio memoria narrativa la novela espa $\% \mathrm{C} 3 \% \mathrm{~B} 1$ ola finisecular. [consultado el 17/03/2019]

CIPLIJAUSKAITÉ, Biruté (1998): "La construcción del yo y la historia en los epistolarios". Monteagudo. 3: 61-72.

CUVARDIC GARCÍA, Dorde (2014): "La narratología desde los años Setenta hasta el siglo XXI". Revista de Filología y Lingüística de la Universidad de Costa Rica. 40: 101-116. https://revistas.ucr.ac.cr/index.php/filyling/article/view/19580 [consultado el 17/03/2019]

GRACIA, Jordi; RÓDENAS, Domingo (2011): Historia de la literatura española. Derrota y restitución de la modernidad. Madrid: Crítica.

GUILLÉN, Claudio (1991): "Al borde de la literaridad: literatura y epistolaridad". Tropelias. 2: 71-92. 
HERMOSIlla ÁlVAREZ, María Ángeles; CEPEDEllo MORENO, María Paz (2013): "Narrativa de mujeres y punto de vista: la novela española reciente". Sociocriticism. XXVIII, 1-2: 255-288. http://revistaseug.ugr.es/index.php/sociocriticism/article/view/2399 [consultado el 17/03/2019]

MARÍN ABETUYA, Diego (2004): "El correo electrónico como nuevo género epistolar en la literatura actual", Miguel Ángel Muro Munilla (coord.), Arte y nuevas tecnologías. X Congreso de la Asociación Española de semiótica. La Rioja: Universidad de La Rioja Fundación San Millán de la Cogolla, 738-749. https:// dialnet.unirioja.es/descarga/articulo/940470.pdf [consultado el 19/02/2019]

MORA, Magdalena (1988): "Juego de cartas". Revista de Occidente. 83:136-143.

MORALES LADRÓN, Marisol (1996): "La dialéctica entre la presencia y la ausencia ficcional del destinatario en el discurso epistolar". 1616: Anuario de la Sociedad Española de Literatura General y Comparada. X: 285-295. www.cervantesvirtual.com/obra/la-dialctica-entre-la-presencia-y-la-ausencia-ficcionaldel-destinatario-en-el-discurso-epistolar-0/ [consultado el 19/02/2019]

PETRUCCI, Armando (2008): Scrivere lettere. Una storia plurimillenaria. Roma-Bari: Laterza.

RIVAS CARMONA, María del Mar (1997): Voz de mujer. Lo femenino en el lenguaje y la literatura. Córdoba: Universidad de Córdoba y Obra Social y Cultura Cajasur.

SANTOS, Care (2011): Habitaciones cerradas. Barcelona: Planeta.

SANTOS, Care; GARCÍA RÍOS, Beatriz (2016): "Care Santos: «Pocos temas hay más allá de la familia y el paso del tiempo»”. Cuadernos hispanoamericanos. 792: 104-113.

VALLÉS CALATRAVA, José R. (2008): Teoría de la narrativa. Una perspectiva sistemática. Madrid-Frankfurt am Main: Iberoamericana-Vervuert.

VIOLI, Patrizia (1984): "L'intimità dell'assenza. Forme della scrittura epistolare". Carte Semiotiche. 0: 90-97.

\section{PERFIL ACADÉMICO Y PROFESIONAL}

Doctora en Ciencias Lingüísticas y Literarias por la Universidad de Udine (Italia) en 2015 con una tesis sobre la relación entre moda y literatura en la obra de Carmen Martín Gaite y Mercè Rodoreda dirigida por la profesora Renata Londero. En 2017 becaria de investigación en la Universidad de Udine para un proyecto de clasificación y comparación de fondos antiguos de interés iberistico, con un catálogo que acaba de publicarse. Actualmente es profesora asociada de Lengua española en la misma universidad. Ha participado en congresos nacionales e internacionales y ha publicado varios artículos sobre distintos ámbitos y autores de la literatura española del siglo XX y XXI.

Fecha de recepción: 16/05/2019

Fecha de aceptación: 24/07/2019 